\title{
Pengaruh Ukuran Ovarium dan Folikel terhadap Penampilan Reproduksi Pada Sapi PO dan SimPO di Kecamatan Jatinom, Kabupaten Klaten
}

\section{The Effect of Ovarium and Folicle Sizes on Reproductive Performance in PO and SimPO Cows at Jatinom Sub-District, Klaten District}

\author{
Topas Wicaksono Priyo Jr ${ }^{1}$, Agung Budiyanto ${ }^{2 *}$, Asmarani Kusumawati ${ }^{2}$ \\ ${ }^{1}$ Fakultas Kedokteran Hewan, Universitas Gadjah Mada, Yogyakarta \\ ${ }^{2}$ Departemen Reproduksi dan Obstetri, Fakultas Kedokteran Hewan, Universitas Gadjah Mada, \\ Jl. Fauna 2 Karangmalang, Yogyakarta \\ *Email : agung_bd2004@yahoo.com
}

Naskah diterima: 5 Mei 2019, direvisi: 31 Agustus 2019, disetujui: 30 Desember 2019

\begin{abstract}
The increasing beef cattle population in Indonesia is not significantly with high demand of meat every year. The insignificant increasing in population is caused by fertility decreasing, infectious disease and the reduction amount of forage land. The factor which causes cattle fertility decreasing can't be separated from the ovarian and follicular diameter which have an effect on high various reproductive appearance. Parameters that used for knowing reproductive appearance of cattle are Service per Conception (S/C) and Calving Interval (CI). The aims of this study was to describe ovary sizes and follicular diameter in cattle, to describe ovary and follicular diameter toward $\mathrm{S} / \mathrm{C}$ and $\mathrm{CI}$ variation. This research uses female cattle, 8 Simmental-PO (SimPO) and 9 Peranakan Ongole breeds (PO), multiparous, are not pregnant, 4-8 years old, Body Condition Score (BCS) 2.5-3.5, peak phase estrus, has no reproductive problems, clear recordings and live in the area of farmer in Jatinom District, Klaten Regency, Central Java Province. Cattle are examined for ovarian size and follicle size using ultrasonography. S/C and CI data were obtained from records of artificial insemination cards (AI). The data obtained were analyzed by $t$ test. The results of this study showed there were no differences in the diameter of ovaries in the size of SimPO and PO cattle $(\mathrm{P}>0.05)$, there were no differences in the diameter of SimPO and PO cattle follicles $(>0.05)$, there were differences in ovarian and follicular diameter sizes with respect to $\mathrm{S} / \mathrm{C}$ and $\mathrm{CI}$ in cattle with good and bad reproductive performance $(\mathrm{P}<0.05)$. The conclusion of the study showed that there was no difference in ovarian and follicular diameter size in SimPO and PO cattle $(\mathrm{P}>0.05)$ but there was an influence on $\mathrm{S} / \mathrm{C}$ and $\mathrm{CI}(\mathrm{P}<0.05)$.
\end{abstract}

Key words: low fertility; ovarian size; follicle size; service per conception; calving interval

\begin{abstract}
Abstrak
Peningkatan jumlah populasi sapi potong di Indonesia setiap tahunnya tidak signifikan dengan tingginya kebutuhan daging di Indonesia. Peningkatan jumlah populasi yang tidak signifikan ini disebabkan oleh penurunan fertilitas, penyakit infeksius, dan jumlah lahan hijauan yang berkurang. Faktor-faktor yang menyebabkan penurunan fertilitas sapi tidak lepas dari ukuran diameter ovarium dan folikel yang dapat berefek pada tingginya variasi penampilan reproduksi. Tolak ukur untuk mengevaluasi penampilan reproduksi sapi yaitu Service per Conception (S/C) dan Calving Interval (CI). Penelitian ini bertujuan untuk mengetahui gambaran ukuran diameter ovarium dan folikel pada sapi, mengetahui gambaran diameter ovarium dan folikel terhadap variasi S/C dan CI. Penelitian ini menggunakan sapi betina sebanyak 8 ekor jenis SimentalPO (SimPO) dan 9 ekor jenis Peranakan Ongole (PO), sudah pernah beranak, tidak bunting, berumur 4-8 tahun, Body Condition Score (BCS) 2,5-3,5, fase puncak
\end{abstract}


estrus, tidak mengalami gangguan reproduksi, rekording jelas dan berada di wilayah peternakan rakyat Kecamatan Jatinom, Kabupaten Klaten, Provinsi Jawa Tengah. Sapi diperiksa ukuran ovarium dan ukuran folikel menggunakan ultrasonografi. Data S/C dan CI diperoleh dari catatan kartu inseminasi buatan (IB). Data yang diperoleh dianalisis menggunakan uji t. Hasil dari penilitian ini menunjukkan tidak ada perbedaan diameter ukuran ovarium sapi jenis SimPO dan PO (P $>0.05)$, tidak ada perbedaan diameter folikel sapi jenis SimPO dan PO $(>0.05)$, ada perbedaan ukuran diameter ovarium dan folikel terhadap $\mathrm{S} / \mathrm{C}$ dan $\mathrm{CI}$ pada sapi dengan penampilan reproduksi baik dan buruk $(\mathrm{P}<0.05)$. Kesimpulan penelitian menunjukkan tidak ada perbedaan ukuran diameter ovarium dan folikel pada sapi SimPO dan $\mathrm{PO}(\mathrm{P}>0.05)$ tetapi terdapat pengaruh terhadap $\mathrm{S} / \mathrm{C}$ dan $\mathrm{CI}(\mathrm{P}<0.05)$.

Kata kunci: penurunan fertilitas; ukuran ovarium; ukuran folikel; service per conception; calving interval

\section{Pendahuluan}

Ketersediaan daging sapi dalam negeri belum cukup untuk memenuhi kebutuhan konsumsi nasional. Tahun 2017 konsumsi daging sapi nasional untuk konsumsi sebanyak 628.276 ton sedangkan produksi daging sapi sebanyak 531.757 ton (Anonim ${ }^{1}$, 2017). Jumlah produksi daging sapi erat kaitannya dengan jumlah populasi sapi potong. Jumlah populasi sapi potong di Indonesia peningkatan setiap tahunnya tidak signifikan, khusus di provinsi Jawa Tengah populasi sapi potong pada tahun 2013 sebanyak 1.500 .077 ekor dan mengalami peningkatan populasi kurang signifikan pada tahun 2017 menjadi 1.718.206 ekor (Anonim ${ }^{2}$, 2017). Peningkatan jumlah populasi yang tidak signifikan ini dipengaruhi oleh lahan penggembalaan terbatas, perubahan lahan penggembalaan menjadi pemukiman penduduk, biaya pakan yang mahal, banyaknya sapi yang dipotong akibat penyakit infeksius, penyakit non infeksius, inefisiensi reproduksi dan gangguan reproduksi. Gangguan dan inefisiensi reproduksi mengakibatkan tertundanya pubertas, rendahnya performa estrus, panjangnya periode postpartum dan tingkat konsepsi yang rendah (Widarini et al., 2017).

Inefisensi reproduksi merupakan permasalahan yang paling banyak dialami oleh peternakan rakyat. Salah satu penyebab inefisiensi reproduksi yaitu penurunan fertilitas. Fertilitas merupakan kemampuan organ reproduksi untuk bekerja optimal dalam menjalankan fungsi fertilisasi (Ramadhani et al., 2017). Salah satu penyebab penurunan fertilitas adalah ukuran ovarium dan folikel yang tidak optimal. Ukuran ovarium dan folikel pada fase praovulatori memiliki efek terhadap kadar estradiol yang akan berfungsi dalam menginduksi perilaku estrus, kematangan oosit, meningkatkan transportasi oosit menuju oviduk, meningkatkan lingkungan uterus untuk persiapan pembentukan embrio dini dan meningkatkan kepekaan reseptor luteinizing hormon (Keskin et al., 2016; Perry et al., 2005). Penurunan fertilitas sapi berpengaruh terhadap penampilan reproduksi. Tolak ukur untuk mengevaluasi penampilan reproduksi yaitu Service per Conception (S/C), Conception Rate (CR), Days Open (DO) dan Calving Interval (CI) (Ihsan dan Wahjuningsih, 2011).

Ukuran ovarium dan folikel memiliki variasi ukuran yang tinggi setiap individu walaupun pada umur yang sama (Mossa et al., 2012). Menurut Keskin et al. (2016) sapi betina dengan tingkat kebuntingan tinggi memiliki ukuran folikel yang kecil, hal ini berbanding terbalik dengan pendapat Perry et al. (2005) yang menyatakan sapi dengan kebuntingan tinggi memiliki ukuran folikel yang besar. Adanya perbedaan pendapat dari penilitian terdahulu, hal ini membuat variasi ukuran ovarium dan folikel sangat tinggi terhadap penampilan reproduksi sapi yang baik, termasuk di negara Indonesia.

Perbedaan pendapat dari beberapa penelitian sebelumnya dan data informasi ilmiah tentang ukuran ovarium, folikel yang berdampak baik dan buruk pada penampilan reproduksi sapi potong belum ada di Indonesia hingga saat ini. Berdasarkan uraian diatas, perlu dilakukan penelitian tentang gambaran ukuran ovarium dan folikel terhadap variasi penampilan reproduksi 
pada sapi potong di Indonesia. Tujuan penelitian ini adalah untuk mengetahui gambaran ukuran ovarium dan folikel pada sapi Peranakan Ongole (PO) dan Simmental Peranakan Ongole (SimPO) dan mengetahui gambaran ukuran ovarium dan folikel terhadap penampilan reproduksi pada sapi PO dan SimPO di Kecamatan Jatinom, Kabupaten Klaten. Manfaat penelitian ini adalah untuk mendapatkan informasi ilmiah tentang gambaran ukuran ovarium dan folikel pada sapi PO dan SimPO dan mendapatkan informasi ilmiah tentang gambaran ukuran ovarium dan folikel terhadap penampilan reproduksi pada sapi PO dan SimPO di Kecamatan Jatinom, Kabupaten Klaten.

\section{Materi dan Metode}

Penelitian dilaksanakan di kawasan peternakan sapi potong Kecamatan Jatinom, Kabupaten Klaten, Provinsi Jawa Tengah. Penelitian ini menggunakan sapi potong betina 8 ekor sapi jenis SimPO dan 9 ekor sapi jenis PO, sudah pernah beranak, tidak bunting, berumur 4-8 tahun, Body Condition Score (BCS) 2,5-3,5, sedang fase puncak estrus, tidak mengalami gangguan reproduksi dan memiliki kartu Inseminasi Buatan (IB). Sapi diberikan pakan hijauan sebanyak $10 \%$ dari berat badan per ekor, pakan konsentrat $1 \%$ dari berat badan per ekor, minum ad libitum, tipe kandang tunggal dan manajemen pemiliharaan metode intensif. Pemeriksaan ultrasonografi (USG) (Welld WED-3000) untuk mengukur diameter ovarium dan folikel. Pengukuran ovarium dan folikel menggunakan metode Keskin et al. (2016) yaitu dengan mengukur rata-rata dua diameter garis horizontal dan vertikal tepi ovarium dan folikel. Penampilan reproduksi S/C dan CI diperoleh dari pencatatan kartu IB. Penampilan reproduksi dengan kategori baik menggunakan metode San et al. (2015) yaitu S/C 1.6-2.0 kali dan kategori buruk diatas 2 kali. Data yang diperoleh dianalisis menggunakan metode uji t.

\section{Hasil dan Pembahasan}

Hasil pengukuran diameter ovarium pada sapi potong jenis SimPO dan PO tersaji dalam Tabel 1. Hasil penilitian ini menunjukkan sapi jenis SimPO memiliki rata-rata diameter ovarium $3.0 \pm 1.4 \mathrm{~cm}$ dan sapi jenis PO memiliki rata-rata diameter ovarium $3.2 \pm 1.0 \mathrm{~cm}$. Hasil analisis menunjukkan tidak ada perbedaan diamater ovarium sapi jenis SimPO dan PO $(\mathrm{P}>0.05)$.

Tabel 1. Ukuran diameter ovarium sapi jenis SimPO dan PO

\begin{tabular}{ccc}
\hline Jenis & Jumlah sapi (ekor) & Diameter ovarium $(\mathbf{c m})$ \\
\hline SimPO & 8 & $3.0 \pm 1.4^{\text {a }}$ \\
PO & 9 & $3.2 \pm 1.0^{\text {a }}$ \\
\hline
\end{tabular}

Keterangan: Huruf yang yang sama pada kolom yang sama menyatakan tidak ada perbedaan $(\mathrm{p}>0.05)$.

Pemeriksaan dengan metode ultrasonografi secara transrektum dilakukanuntuk melihat struktur ovarium, folikel dan korpus luteum (Putro, 2014). Hasil pengukuran diameter ovarium sapi jenis SimPO dan PO pada penelitian ini sesuai dengan Ismaya (2014) menyatakan ukuran diameter ovarium sapi jenis SimPO memiliki rentang 3-4 $\mathrm{cm}$ dan sapi jenis PO memiliki rentang 3-3,2 $\mathrm{cm}$. Menurut Jallaludin (2014) ukuran ovarium masing-masing hewan sangat dipengaruhi oleh spesies, umur, fase siklus reproduksi, paritas dan tingkat gizi pakan.

Hasil pengukuran diameter folikel pada sapi potong jenis SimPO dan PO tersaji dalam Tabel 2. Hasil penelitian ini menunjukkan sapi jenis SimPO memiliki rata-rata diameter folikel $14 \pm 4.5$ $\mathrm{mm}$ dan sapi jenis PO memiliki rata-rata diameter folikel $13 \pm 4.2 \mathrm{~mm}$. Hasil analisis menunjukkan tidak ada perbedaan diameter folikel sapi jenis SimPO dan PO $(\mathrm{P}>0.05)$.

Tabel 2. Ukuran diamet er folikel pada sapi jenis SimPO dan PO

\begin{tabular}{ccc}
\hline Jenis & Jumlah sapi (ekor) & Diameter folikel (mm) \\
\hline SimPO & 8 & $14 \pm 4.5^{\text {a }}$ \\
PO & 9 & $13 \pm 4.2^{\text {a }}$ \\
\hline
\end{tabular}

Keterangan: Huruf yang yang sama pada kolom yang sama menyatakan tidak ada perbedaan $(\mathrm{p}>0.05)$.

Hasil penelitian ini menunjukkan diameter ukuran folikel sapi jenis PO yaitu $13 \pm 4.2 \mathrm{~mm}$ lebih besar dari hasil penilitian Imron et al. (2016) yang menyataka rata-rata diameter folikel dominan sapi jenis PO yaitu 12-12.3 mm. Hasil penelitian ini sejalan menurut Bo et al. (2003) dan Sartori et al. (2001) menyatakan karateristik reproduksi sapi eropa (Bos taurus) dengan sapi zebu (Bos indicus) berbeda dari segi lama siklus estrus, perilaku estrus, perkembangan dominan folikel dan perkembangan korpus luteum. Spesies Bos 
Tabel 3. Diameter ovarium dan diameter folikel terhadap S/C dan CI pada sapi.

\begin{tabular}{cccccc}
\hline $\begin{array}{c}\text { Keterangan penampilan } \\
\text { reproduksi }\end{array}$ & $\begin{array}{c}\text { Jumlah sapi } \\
\text { (ekor) }\end{array}$ & $\begin{array}{c}\text { Diameter ovarium } \\
(\mathbf{c m})\end{array}$ & $\begin{array}{c}\text { Diameter folikel } \\
(\mathbf{m m})\end{array}$ & S/C (kali) & CI (bulan) \\
\hline Baik & 6 & $4.1 \pm 0.2^{\mathrm{a}}$ & $18.8^{\mathrm{a}} \pm 1.2^{\mathrm{a}}$ & $1.6 \pm 0.5^{\mathrm{a}}$ & $14.1 \pm 0.7^{\mathrm{a}}$ \\
Buruk & 11 & $2.5 \pm 0.7^{\mathrm{b}}$ & $11.6 \pm 3.4^{\mathrm{b}}$ & $6.3 \pm 1.9^{\mathrm{b}}$ & $28.7 \pm 9.9^{\mathrm{b}}$ \\
\hline
\end{tabular}

Keterangan : Huruf yang berbeda pada kolom yang sama menyatakan perbedaan $(\mathrm{P}<0.05)$.

indicus memiliki diameter folikel dominan yang lebih kecil dibandingkan spesies Bos taurus. Sapi SimPO merupakan persilangan sapi Simmental (Bos taurus) dan Peranakan Ongole (Bos indicus), dikarenakan telah terjadi persilangan antara spesies Bos taurus dan Bos indicus reproduksi sapi SimPO telah memiliki kedekatan genetik dengan sapi PO sehingga ukuran folikel sapi SimPO tidak sebesar sapi Simmental (Bos taurus). Hal ini menyebabkan tidak ada perbedaan ukuran folikel sapi jenis SimPO dan PO.

Hasil ukuran diameter ovarium dan folikel terhadap penampilan reproduksi $(\mathrm{S} / \mathrm{C}$ dan $\mathrm{CI})$ pada sapi tersaji dalam Tabel 3. Hasil penelitian ini menunjukkan sapi dengan kategori penampilan reproduksi baik memiliki diameter ovarium $4.1 \pm 0.2 \mathrm{~cm}$, diameter folikel $18.8 \pm 1.2, \mathrm{~S} / \mathrm{C} 1.6 \pm 0.5$ kali dan CI 14.1 \pm 0.7 bulan. Sapi dengan kategori penampilan reproduksi buruk memiliki diameter ovarium $2.5 \pm 0.7 \mathrm{~cm}$, diameter folikel $11.6 \pm 3.4$, S/C $6.3 \pm 1.9$ kali dan CI $28.7 \pm 9.9$ bulan. Hasil analisis statistika menunjukkan adanya perbedaan ukuran diameter ovarium dan folikel terhadap S/C dan CI pada sapi dengan penampilan reproduksi baik dan buruk $(\mathrm{P}<0.05)$.

Hasil penelitian ini sesuai dengan pendapat Keskin et al. (2016) melaporkan bahwa diameter folikel antara 13.5-17.5 mm mempunyai presentase kebuntingan yang terbaik dan Echternkamp et al. (2009) menyatakan rentang diameter folikel yaitu 10.3-18.1 mm. Diameter folikel $<12 \mathrm{~mm}$ memiliki tingkat kebuntingan yang rendah, sedangkan diameter folikel $12-18.8 \mathrm{~mm}$ memililki tingkat kebuntingan yang tinggi.

\section{Kesimpulan}

Tidak ada perbedaan yang signifikan ukuran ovarium dan folikel pada sapi PO dan SimPO namun mempengaruhi $\mathrm{S} / \mathrm{C}$ dan $\mathrm{CI}$.

\section{Daftar Pustaka}

Anonim ${ }^{1}$. (2017). Outlook Daging Sapi Komoditas Pertanian Subsektor Peternakan. Pusat Data dan Sistem Informasi Pertanian. Jakarta

Anonim $^{2}$. (2017). Produksi Daging Sapi Menurut Provinsi. Retrivied April 15, 2018, from http://www1.pertanian.go.id/ap_pages/ $\mathrm{mod} /$ datanak

Bo, G. A., Baruselli, P. S., Martinez, M. F. (2003). Pattern and Manipulation of Follicular Development in Bos Indicus Cattle. Animal Reproduction Science. 78: 307-326

Echternkamp, S. E., Cushman, R. A., Allan, M. F. (2009). Size of Ovulatory Follicle in Cattle Expressing Multiple Ovulations Naturally and its Influence on Corpus Luteum Development and Fertility. Journal Animal Science. 87: 3556-3568

Ihsan, M. N dan Wahjuningsih, S. (2011). Penampilan Reproduksi Sapi Potong di Kabupaten Bojonegoro. Jurnal Ternak Tropika. 12 (2):76-80

Imron, M., Supriatna, I., Amrozi., Setiadi., M. A. (2016). Follicular Dynamic and Repeatability of Follicular Wave Development in Peranakan Ongole (PO) Cattle. Jurnal Ilmu Ternak Veteriner. 21(1): 26-33

Ismaya. Bioteknologi Inseminasi Buatan Pada Sapi dan Kerbau. (2014). Gadjah Mada University Press. Yogyakarta

Jalaluddin. (2014). Morfometri dan Karakteristik Histologi Ovarium Sapi Aceh (Bos Indicus) Selama Siklus Estrus. Jurnal Medika Veterinaria. 8(1): 66-68

Keskin, A., Mecitoglu, G., Bilen, E., Guner, B. (2016). The Effect of Ovulatory Follicle Size at The Time of Insemination on 
Pregnancy Rate in Lactating Dairy Cows. Turkish Journal Veterinary and Animal Sciences. 40: 68-74

Mossa, F., Walsh, S. W., Butler S. T., Berry, D. P., Carter, F., Lonergan, P., Smith, G. W., Ireland, J. J., dan Evans, A. C. O. (2012). Low Number of Ovarian Follicles $\geq 3 \mathrm{~mm}$ in Diameter are Associated With Low Fertility in Dairy Cows. Jounal Dairy Science. 95: 2355-2361

Perry, G. A., Smith, M. F., Lucy, M. C., Green, J. A., Parks, T. E., MacNeil, M. D., Roberts, A. J. Geary, T. W. (2005). Proceedings of the National Academy of Scieces of the United States of America. 102(14): 5268-5273

Putro,P.P.(2014).Akurasi Diagnosa Ultrasonografi Transrektum untuk Pemeriksaan Struktur Ovaria Sapi. Jurnal Sain Veteriner. 32(2): 146-152

Ramadhani, S. A., Supriatna, I., Karja, N. W. K., Winarto, A. (2017). Pengendalian Folikulogenesis Ovarium dengan Pemberian Ekstrak Biji Kapas. Jurnal Sain Veteriner. 35(1): 71-90
San, D. B. A., Yase Mas, I. K. G., Setiatin, E. T. (2015). Evaluasi Keberhasilan Inseminasi Buatan pada Sapi Simental-PO (SimPO) di Kecamatan Patean dan Plantungan, Kabupaten Kendal, Jawa Tengah. Animal Agriculture Journal. 4(1): 171-176

Sartori, R. Fricke, P. M., Ferreira, J. C. P., Ginther, O. J. Wiltbank, M. C. (2001). Follicular Deviation and Acquisition of Ovulatory Capacity in Bovine Follicles. Biology of Reproduction. 65: 1403-1409

Widarini, W., Beda, I. R., Wijayanti, A. D. (2017). Efektivitas Terapi Multivitamin, Obat Cacing dan Premix Pada Sapi Terdiagnosa Hipofungsi Ovarium di Wilayah Kecamatan Prambanan, Yogyakarta. Jurnal Sain Veteriner. 35(2): 230-235 